\title{
Teff: Suitability for Different Food Applications and as a Raw Material of Gluten-free, a Literature Review
}

\author{
Kamila de Oliveira do Nascimento ${ }^{1, *}$, Sany do Nascimento Dias Paes ${ }^{2}$, Indianara Reis de Oliveira ${ }^{3}$, \\ Isabela Pereira Reis ${ }^{1}$, Ivanilda Maria Augusta ${ }^{1}$ \\ ${ }^{1}$ Department of Food Technology, Institute of Technology, Universidade Federal Rural do Rio de Janeiro, Seropédica, RJ, Brazil \\ ${ }^{2}$ Post-Graduation in Phytotherapy, Supplementation and Functional Foods in Clinical Practice, UniFOA, Tangerinal, \\ Volta Redonda - RJ -Brazil \\ ${ }^{3}$ Foreign Trade, Universidade Estácio de Sá, Resende - RJ -Brazil \\ *Corresponding author: kamila.nascimento@yahoo.com.br
}

\begin{abstract}
Teff has naturally higher nutritional value when compared to many other grains, and doesn't need to be fortified. Naturally gluten-free, the grain of teff can substitute for wheat flour and other cereals in anything from bread and pasta to waffles and pizza bases, as well as foods for people with celiac disease. Thus, the main objective of this article is to review researches on teff, evaluate its suitability for different food applications, and give direction for further research on its applications for gluten free food market. Teff grain size is known to be extremely small with mean length ranging $0.61-1.17 \mathrm{~mm}$ and it is considered a superior grain due to its nutritional merits. Teff is rich in carbohydrate, fiber and contains more iron, calcium and zinc than other cereal grains, including wheat, barley and sorghum. Teff has an excellent balance of essential amino acids and is a good source of calcium and iron, which may explain the low occurrence of anemia in areas of Ethiopia where to regular teff consumption. Hence, Teff is an ideal and healthy ingredient for many gluten-free recipes.
\end{abstract}

Keywords: Teff, gluten-free, Teff flour, bakey products, antioxidant

Cite This Article: Kamila de Oliveira do Nascimento, Sany do Nascimento Dias Paes, Indianara Reis de Oliveira, Isabela Pereira Reis, and Ivanilda Maria Augusta, "Teff: Suitability for Different Food Applications and as a Raw Material of Gluten-free, a Literature Review.” Journal of Food and Nutrition Research, vol. 6, no. 2 (2018): 74-81. doi: 10.12691/jfnr-6-2-2.

\section{Introduction}

Teff [Eragrostis tef (Zuccagni) Trotter], is an indigenous and major food crop in Ethiopia and Eritrea, Africa [1]. The whole grain is ground into flour that can be used as a base ingredient for leavened flatbreads such as injera, added as a thickening agent to soups and sauces, fermented to make beer and ethnic beverages, or made into porridge and puddings [2].

Teff is a tropical cereal and it is considered a low-risk crop from the perspectives that it can be cultivated in a broad range of ecological surroundings and under tough environmental conditions where most other cereals fail [1]. In the United States, teff is cultivated in Montana, South Dakota, and Idaho [3].

Teff belongs to the grass family, Poaceae, sub-family Chloridoideae (Eragrostoideae), tribe Eragrostidae, subtribe Eragrostae, and genus Eragrostis [4]. It is the only cultivated cereal in the genus Eragrostis and consists of about 350 varieties [5]. Cultivated over approximately 2.8 million hectares, teff accounts for 28.5 percent of land area under cereal cultivation, the largest share of all staple grains in Ethiopia [6].

Is cultivated by more than five million small-scale farmers annually and constitutes the staple food for more than half of the population of 80 million. The crop is preferred by both farmers and consumers due to its beneficial traits associated with its agronomy and utilization. The genetic and phenotypic diversity of teff in Ethiopia is a national treasure of potentially global importance [7]. Teff is tolerant to many extreme environmental conditions including water-logging and storage pests [8]. Although Teff performs well on various soil types, the average grain yield in the country basis is about $0.7 \mathrm{mg} \mathrm{ha}^{-1}$. The yield of teff is even lower in the drier part of the country. This low yield is attributed to nutrient deficiencies, mainly of nitrogen (N) and phosphorous (P), and to the susceptibility of the crop to lodging at higher $\mathrm{N}$ [5], among others, due to its low genetic yield potential [9].

The grain proteins offer an excellent balance among the essential amino acids [10]. Teff is rich in carbohydrates, fibre and has a complete set of essential amino acids. Teff is also particularly high in iron and has more calcium, copper and zinc than other cereal grains $[11,12]$. They also contain polyphenols (produced as secondary plant metabolites) which affect the nutritional properties [13].

The demand for gluten-free foods is certainly increasing. Interest in teff has increased noticeably due to its very attractive nutritional profile and gluten-free nature of the grain, making it a suitable substitute for wheat and other cereals in their food applications as well as foods for people with celiac disease $[14,15]$. 
Many gluten-free products may not meet the recommended daily intake for fiber, minerals, and vitamins. Thus, they need to be fortified to fulfill the requirements of the daily intake $[16,17]$. Teff has naturally higher nutritional value when compared to many other grains, and doesn't need to be fortified [15].

Thus, the main objective of this article is to review researches on teff, evaluate its suitability for different food applications, and give direction for further research on its applications for food gluten free market.

\section{Material and Methods}

\subsection{Methods}

This literature review was formulated through literature searches using Science direct. The following keywords were used: "Teff, gluten free, teff flour, bakey products and antioxidant". The logical term operant and was used in the search of items to match keywords. The period of time analyzed was from 2002 to 2017.

\section{Development}

\subsection{Teff: Phytochemical Composition and Antioxidant Capacity}

Teff [Eragrostis tef (Zucc.) Trotter] belongs to the family of Poaceae, subfamily Eragrostoidae, tribe Eragrosteae, and genus Eragrostis [18]. The color of teff can vary from White (ivory) to dark brown (black) depending on the variety. In Ethiopia, three major categories can be identified: white (nech), red (quey) and mixed (sergegna). White teff generally grows only in the Ethiopian highlands and require relatively good growing conditions. However, in recent years, red teff, which is believed to be more nutritious, is also gaining popularity among health conscious consumers in Ethiopia [19].

Teff grain (Figure 1) size is known to be extremely small with mean length ranging $0.61-1.17 \mathrm{~m}$ and mean width ranging $0.13-0.59 \mathrm{~mm}$, that gives an average thousand kernel weight of $0.264 \mathrm{~g}$ [10]. Teff grain commands premium price among other cereals cultivated in Ethiopia. There is a growing interest on teff grain utilizations because of nutritional merits (whole grain), the protein is essentially free of gluten the type found in wheat (alternative food for consumers allergenic to wheat glutens) [20].

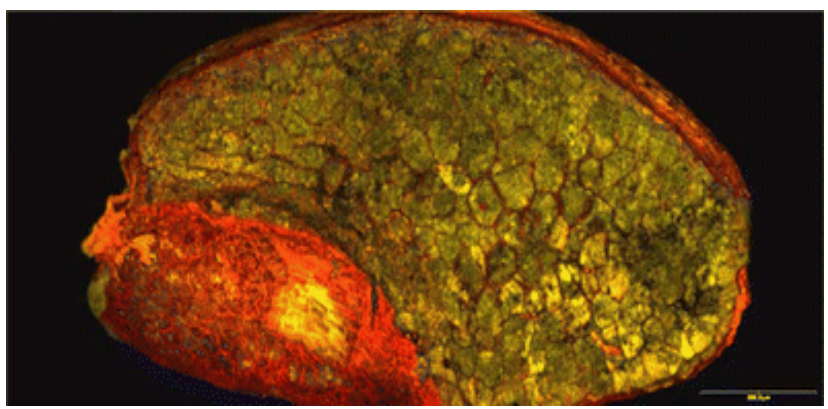

Figure 1. Teff grain: Longitudinal section with germ and endosperm (SEM image) (Source: [15])
A proximate analysis revealed the high nutritive value of the seeds of Eragrostis tef: carbohydrates (57.27\%), protein (20.9\%), essential amino acids (8.15\%) with major leucine and lysine (1.71 and $1.35 \%$, respectively), vitamin B1 (1.56\%) and potassium and calcium (32.4 and 9.63\%, respectively). The seeds yielded $22 \%$ w/w of fixed oil rich in unsaturated fatty acids (72.46\%), among which oleic acid, was predominant (32.41\%), followed by linolenic acid $(23.83 \%)$ [22]. The grain proteins are also presumed easily digestible because prolamins are very small [20].

In Table 1, tested samples of teff have shown protein content between 10.5 and $11.1 \mathrm{~g} / 100 \mathrm{~g} / 100 \mathrm{~g}$, carbohydrates content 73.1 and $73.6 \mathrm{~g} / 100 \mathrm{~g}$, iron content between 18.9 and 58.9mg/100g and calcium content between 156 and $157 \mathrm{mg} / 100 \mathrm{~g}$ which are higher than most grains [23].

Table 1. Nutritional contentes of diferent teff varieties per $100 \mathrm{~g}$

\begin{tabular}{lcc}
\hline Nutrient Content & White Teff & Brown Teff \\
\hline Energy (kcal) & 339 & 336 \\
\hline Moisture (\%) & 10.4 & 11.1 \\
\hline Protein (g) & 11.1 & 10.5 \\
\hline Fat (g) & 2.4 & 2.7 \\
\hline Carbohydrate (g) & 73.6 & 73.1 \\
\hline Fiber & 3.0 & 3.1 \\
\hline Ash (g) & 2.5 & 3.1 \\
\hline Calcium (mg) & 156 & 157 \\
\hline Phosphorus (mg) & 366 & 348 \\
\hline Iron (mg) & 18.9 & 58.9 \\
\hline
\end{tabular}

Source: [23].

Thus, in Ethiopia the prevalence of Fe-deficiency anaemia is lower, which is attributed to regular teff consumption. Teff is particularly abundant in Fe (50mg/100g). Furthermore, the fermentation process used during bread making promotes phytate breakdown, further increasing the bioavailability of Fe [24].

A chemical study of the red type of the seeds of Eragrostis tef led to the isolation of seven compounds from its ethanol extract, namely $\beta$-sitosterol (1), $\beta$-amyrin3-O-(2'-acetyl (glucoside (2), $\beta$-sitosterol-3-O- $\beta$-D-glucoside (3), naringenin (4), naringenin-4'-methoxy-7-O- $\alpha$-L-rhamnoside (5), eriodictyol-3',7-dimethoxy-4'-O- $\beta$-D-glucoside (6) and isorhamnetin-3-O-rhamnoglucoside (7), which are reported for the first time in the genus Eragrostis [22].

Boka, Woldegiorgis, and Haki, [25] compared antioxidative potential of methanolic extracts of three teff grain (Eragrostis tef) varieties (white, brown and red teff). The level of IC50 values of free radical and reducing power of various teff varieties varied from 0.6 to $0.88 \mathrm{mg} / \mathrm{ml}$ and 2.25 to $2.5 \mathrm{mg} / \mathrm{ml}$ respectively. The highest free radical scavenging activities $(0.6 \mathrm{mg} / \mathrm{ml})$ and reducing power $(2.25 \mathrm{mg} / \mathrm{ml})$ was observed in red teff while the lowest scavenging activities and reductive potential were shown in white teff $(0.86 \mathrm{mg} / \mathrm{ml})$ and $(2.5 \mathrm{~g} / \mathrm{ml})$, respectively. Total phenol content was higher in red teff $(11.47 \mathrm{mg}$ GAE/g) as compared to brown teff (9.72mg GAE/g) and white teff $(8.28 \mathrm{mg} / \mathrm{GAE} / \mathrm{g})$. Total flavonoids for white, brown and red teff were $1.03 \mathrm{mg} / \mathrm{CE} / \mathrm{g}, 1.78 \mathrm{mg} \mathrm{CE} / \mathrm{g}$ and 2.13mg CE/g, respectively. According El-Alfy, Ezzat, \& Sleem, [22] the ethanolic extract and fixed oil of the seeds 
of Eragrostis tef exhibited anti-hyperlipedaemic and antihyperglycaemic activities.

The total antioxidant capacity and total phenolics content (TPC) of teff [Eragrostis tef] were evaluated. Teff had the highest ferric reducing antioxidant power (FRAP). The FRAP and TPC of teff $(1.8 \mathrm{mmol}$ Trolox equivalence/100 g dry matter (DM) and $123.6 \mathrm{mg}$ gallic acid equivalent/100g DM, respectively) [26].

White and brown Eragrostis teff were assessed for total flavonoid and phenolic content, HPLC profile of the most common phenolics and antioxidant activity including both free and bound phenolics. Antioxidant activity was evaluated in correlation with free and bound phenolics and in vitro digestibility was determined. Content of flavonoids (0.52$1.02 \mathrm{mg} \mathrm{RE} / \mathrm{g}$ ) and phenolics (0.90-1.42mg GAE/g) as well as antioxidant activity $(1.70-4.37 \mu \mathrm{mol} \mathrm{TEAC} / \mathrm{g}$ using ABTS method) was higher in free phenolic fraction. The main free phenolics in brown teff were trans-p-coumaric, protocatechuic, ferulic and gallic acids, while the major free phenolics in white teff were rutin, protocatechuic and ferulic acids. The main bound phenolics in brown teff were ferulic and gallic acids, quercetin and catechin, in white teff ferulic acid, rutin, catechin and quercetin. Cooked teff showed very high level of in vitro organic matter digestibility (80.5-85.1\%), whereas brown teff was significantly more digestible than white teff $(\mathrm{P}<0.05)$ [13].

\subsection{Teff Flour}

Although similar to wheat in food value, teff has a higher vitamin and mineral content. When wheat is processed, the germ (the embryo of the berry, which contains a high concentration of vitamins) is removed from the endosperm. The endosperm is then milled into flour. In contrast, teff is almost always produced as a whole-grain flour. When it is milled, it is difficult to separate the bran and germ because of the relatively small size of the grain. Because there is a greater portion of germ in the milled flour, the nutrient content of teff flour is also higher. Teff has an excellent balance of essential amino acids and is a good source of calcium and iron, which may explain the low occurrence of anemia in areas of Ethiopia where to regular teff consumption [3].

Because of the tiny dimensions of teff seeds, the whole meal flour is characterized by the presence of significant amounts of coating layers and sprout, resulting into high levels of insoluble polysaccharides [27]. The proportion of aqueous alcohol-soluble teff protein was approx $40 \%$ and it was rich in glutamine and leucine [2].

Recently, the use of teff in food systems is gaining popularity as both a naturally gluten-free alternative to wheat products and a nutrient-rich ingredient in the baby food industry. Teff flour, despite it being gluten-free, has been reported to produce high-quality leavened flatbread that stales much slower than if made from other cereals, in particular sorghum, which is commonly used to produce gluten-free baked goods and traditional flatbreads [2].

Teff is mainly processed into different foods and beverages, such as breads, sweet unleavened bread, porridges, pancakes, biscuits, cookies, cakes, stir-fry dishes, casseroles, soups, stews and puddings [1].

Teff (Eragrostis tef) flour has been studied as a valuable ingredient to improve the quality of gluten-free products in several studies, mainly due to its superior nutritional quality. The technological properties of teff indicate that there is a great potential to be used in different food applications, particularly in baked products [12].

Teff grain flour is widely used in Ethiopia for making injera (staples for the majority of Ethiopians, a fermented, pancake-like, soft, sour, circular flatbread), sweet unleavened bread, local spirit, porridges and soups [20]. Teff flour is not only gluten free but is also naturally higher in calcium, iron and fiber and can be a good alternative in gluten free products [28].

The moisture contents and proximate composition among the three varieties of teff flours are presented in Table 2.

Second Abebe and Ronda, [29] the moisture contents among the three varieties of teff flours were not differ significantly. The protein contents of the three teff flours was $8.9 \%$ to $10.5 \%$. The teff flours had significantly higher ash content and the fat contents of the three teff cultivars was $2.63 \%$ to $3.24 \%$. A significant $(p<0.05)$ variation was observed among the crude fat contents of teff varieties. The germ, which is totally included in teff flour, could explain its higher fat content. Teff-white (DZ-Cr-37) had significantly lower total carbohydrate than the other teff varieties. The starch content of the cereals ranged between $74 \%$ to $75.5 \%$, among the teff cultivars. Starch content in Teff-white (DZ-Cr-37) flour was significantly lower than the other two cultivars and the amylose contents in the starches of the three types of teff flours did not differ significantly. Table 3 shows the ash content of the teff flour as well as the mineral composition.

Table 2. Chemical composition of teff flours*

\begin{tabular}{|c|c|c|c|c|c|c|c|}
\hline Flour & Moisture (\%) & $\begin{array}{l}\text { Proteins } \\
(\% \mathrm{w} / \mathrm{w})\end{array}$ & $\begin{array}{c}\text { Ash } \\
(\% \mathrm{w} / \mathrm{w})\end{array}$ & $\begin{array}{c}\text { Fat } \\
(\% \mathrm{w} / \mathrm{w})\end{array}$ & $\begin{array}{c}\text { Carbohydrates } \\
(\% \mathrm{w} / \mathrm{w})\end{array}$ & $\begin{array}{c}\text { Starch } \\
(\% \text { w/w) }\end{array}$ & $\begin{array}{c}\text { Amylose } \\
\text { (\% of starch) }\end{array}$ \\
\hline $\begin{array}{l}\text { Teff-brown } \\
\text { (DZ-01-99) }\end{array}$ & $10.5 \pm 0.1$ & $8.9 \pm 0.3$ & $2.71 \pm 0.19$ & $2.84 \pm 0.08$ & $85.6 \pm 0.6$ & $75.5 \pm 0.1$ & $21.6 \pm 0.3$ \\
\hline $\begin{array}{c}\text { Teff-white } \\
\text { (DZ-Cr-37) }\end{array}$ & $10.3 \pm 0.1$ & $10.5 \pm 0.2$ & $3.52 \pm 0.01$ & $2.63 \pm 0.06$ & $83.4 \pm 0.2$ & $74.0 \pm 0.3$ & $21.8 \pm 0.3$ \\
\hline $\begin{array}{c}\text { Teff-white } \\
\text { (DZ-Cr-387) }\end{array}$ & $10.4 \pm 0.1$ & $8.9 \pm 0.2$ & $2.63 \pm 0.09$ & $3.24 \pm 0.06$ & $85.3 \pm 0.3$ & $75.5 \pm 0.4$ & $21.1 \pm 0.4$ \\
\hline
\end{tabular}

*(\% on dry basis, except amylose).

Source: [29]. 
Table 3. Ash content [\% (w/w) based on fresh weight] and mineral composition of flours

\begin{tabular}{lc}
\hline & Teff flour components $(\mathbf{m g} / \mathbf{1 0 0 g})$ \\
\hline Ash & $0.21 \pm 0.05$ \\
\hline Calcium & $154.30 \pm 2.0$ \\
\hline Magnesium & $168.97 \pm 14.5$ \\
\hline Sodium & $5.98 \pm 2.1$ \\
\hline Potassium & $382.77 \pm 4.5$ \\
\hline Iron & $8.53 \pm 2.0$ \\
\hline Copper & $0.93 \pm 0.1$ \\
\hline Manganese & $3.45 \pm 0.4$ \\
\hline Zinc & $4.15 \pm 0.1$ \\
\hline Chloride & $48.10 \pm 39.1$ \\
\hline Phosphorus & $361.70 \pm 11.0$ \\
\hline
\end{tabular}

Source: [30].

Verified that ash content ranged from $0.21 \mathrm{mg} / 100 \mathrm{~g}$, phosphorus contents were high with concentrations up to $361.70 \mathrm{mg} / 100 \mathrm{~g}$. Potassium and sodium, two elements of concern with regard to health care, were also detected in the flours screened. Potassium, magnesium and calcium contents were high, ranging from $382.77 \mathrm{mg} / 100 \mathrm{~g}$, $168.97 \mathrm{mg} / 100 \mathrm{~g}$ and $154.30 \mathrm{mg} / 100 \mathrm{~g}$, respectively. From this point of view, teff flour is interesting for the production of gluten free products, it contains over 30 times more calcium than rice and over 47 times more than maize flour. $100 \mathrm{~g}$ contribute to $15 \%$ of the daily recommended intake. This study however showed that flours made from teff are even higher in their iron content, $8.5 \mathrm{mg} / 100 \mathrm{~g}$ [30]. According Bultosa [20] teff grain micronutrient is also apparently high, particularly in iron, a result of agronomic practices used in Ethiopia and fermentation on injera making. Because of this, the prevalence of iron deficient anemia among teff injera consumers in Ethiopia is low.

In the following Table 4, it appears the teff flour vitamin.

The viscoamylographic tracing of untreated teff flour is characterized by a low peak viscosity, a low loss of viscosity at high temperatures (breakdown), and a limited tendency to retrogradation (setback) compared to the pasting profiles of other cereals [18].

Teff flour has high water absorption capacity, which relates to higher swelling degree of gel phase of teff starches and possibly small and uniform size of teff starch granules, hence, providing larger surface area and the higher water absorption. Teff starch has a slow retrogradation tendency, hence, it could have a potentially positive impact on shelf life of baked products [32,33].

Teff flour is high in resistant starch, up to $40 \%$ of the carbohydrates in teff are composed of resistant starches [34]. Starch isolated from five grain teff varieties was characterized. Grain teff starch is formed of compound granules, comprising many polygonal shape $(2-6 \mu \mathrm{m}$ in diameter) simple granules (Figure 2). The crude composition is similar to that of normal native cereal starches. The amylose content ranges from 24.9-31.7\%. Gelatinisation temperature range was $68.0-74.0-80.0^{\circ} \mathrm{C}$, typical of tropical cereal starches, and resembling the temperature range of rice starch [32].

Table 4. Vitamins in teff flour

\begin{tabular}{cccc}
\hline Vitamin & Content (mg/100g) & Advised daily amount for a 75 kg human (mg) & Available in 150 g of teff flour (\%) \\
\hline Thiamin (B1) & 0.51 & 1.0 & $76 \%$ \\
\hline Riboflavin (B2) & $<0.1$ & 1.5 & $10 \%$ \\
\hline Niacin (B3) & 0.80 & 16 & $8 \%$ \\
\hline Pyridoxin (B6) & $<0.1$ & 3 & $10 \%$ \\
\hline Ascorbic Acid (C) & 0.25 & 70 & $1 \%$ \\
\hline Folic Acid (B9) & $<0.02$ & 0.4 & $85 \%$ \\
\hline
\end{tabular}

Source: [31].

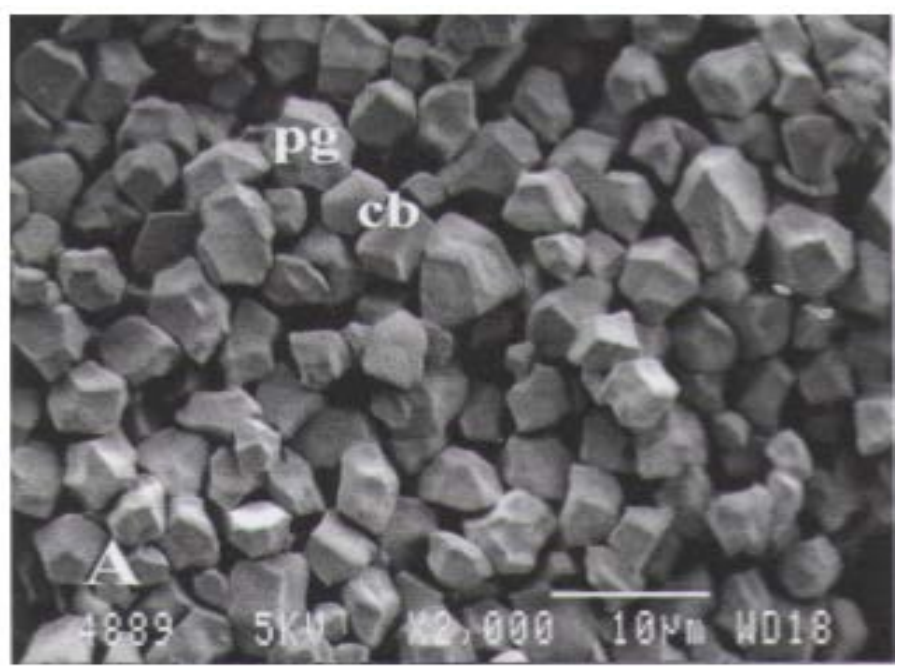

Figure 2. Individual teff starch granules, where pg = polygonal granules and cb = cubic granules Source: [32] 
Tef starch has higher water absorption index (WAI) (mean 108\%) and lower water solubility index (WSI) (mean $0.34 \%$ ) than maize starch [32]. The starch X-ray diffraction pattern was characteristic of A type starch with a mean crystallinity of 37\% [35,36], apparently lower than the crystallinity of maize starch and more similar to that reported for rice and sorghum starches. The starch DSC gelatinisation temperature was high, like for other tropical cereals; To, Tp, Tc and $\Delta \mathrm{H}$ were in the range 63.8-65.4, 70.2-71.3, 81.3-81.5 ${ }^{\circ} \mathrm{C}$ and 2.28-7.22 J/g, respectively [35].

\subsection{Application of Teff in of Gluten-free Bakey Products}

In the following Table 5, studies convering of application of teff in of gluten-free bakey products.

According Hager et al. [37] due to increased awareness of consumers about the relationship between food and health as well as the requirements of people following a gluten-free diet, the production of cereal products from raw materials other than wheat is of interest.

However, the elimination of the viscoelastic gluten protein represents a major technological challenge, as the wheat protein gluten is essential for structure formation. The gluten matrix is a major determinant of the important rheological characteristics of dough, such as elasticity, extensibility, resistance to stretch, mixing tolerance and gas-holding ability [38].

Gluten removal results in major problems for bakers, and currently, many gluten-free products available on the market are of low quality exhibiting poor mouthfeel and flavor. Thus, an increasing trend in research is focusing on the application of alternative grains potentially healthy to elaborate gluten-free products [39].

Table 5. Studies convering of application of teff in of gluten-free bakey products

\begin{tabular}{cll}
\hline Developed products & \multicolumn{1}{c}{ Assay } & \multicolumn{1}{c}{ Conclusion } \\
\hline \multirow{2}{*}{ Cookies } & $\begin{array}{l}\text { Was examined the effect of 25 and 50\% } \\
\text { replacement with teff flour on the } \\
\text { physical, textural and sensory properties } \\
\text { of gluten free sugar and peanut butter } \\
\text { cookies. }\end{array}$ & $\begin{array}{l}\text { Panelists preferred the control and 25\% teff cookie over the } \\
50 \% \text { in case of sugar cookie, but no such preference was } \\
\text { observed in case of peanut butter cookies. These results show } \\
\text { that nutrient dense teff flour can be a good alternative and can } \\
\text { also improve the taste and flavor of gluten free cookies. }\end{array}$ \\
\hline \multirow{2}{*}{ Muffins } & $\begin{array}{l}\text { This study examined the effects of } \\
\text { substitution of rice flour (control) with } \\
\text { teff flour at 25\%, 50\%, 75\% and 100\% } \\
\text { on the physical, textural, and sensory } \\
\text { characteristics of gluten free muffins. }\end{array}$ & $\begin{array}{l}\text { This study demonstrates that substituting 50\% rice flour with } \\
\text { teff not only produces acceptable gluten free muffins, but } \\
\text { these are more nutritious because of their higher protein } \\
\text { (27\%), iron (2095\%), calcium (25\%) and fiber (221\%) } \\
\text { contents. }\end{array}$ \\
\hline [4]
\end{tabular}

Compositional analysis showed that regarding fibre and mineral content, oat and teff samples are nutritionally superior to wheat. Upon cooking, a distinct outer layer can be Was determined formulations for the
Pasta flour. gelatinisation. Thus, the results clearly showed that teff and oat flour can be used to produce gluten-free pasta of acceptable texture.

\begin{tabular}{|c|c|c|c|}
\hline Injera & $\begin{array}{l}\text { The effect of grain tef flour substitution } \\
\text { with flaxseed on quality and } \\
\text { functionality of injera was analyzed. }\end{array}$ & $\begin{array}{l}\text { The 9\% flaxseed-substituted injera showed good proximate } \\
\text { nutritional and energy contents of functional potential of high } \\
\text { in dietary fibre, alpha linolenic acid, lignans, proteins and TP } \\
\text { of antioxidant nature. }\end{array}$ & [41] \\
\hline Bread & $\begin{array}{l}\text { Sourdoughs were produced from } \\
\text { buckwheat, oat, quinoa, sorghum, teff } \\
\text { and wheat flour using the } \\
\text { heterofermentative lactic acid bacteria } \\
\text { Lactobacillus plantarum FST } 1.7 \text { and } \\
\text { added to a basic bread formulation of } \\
\text { flour from the same grain type ( } 20 \% \\
\text { addition level). }\end{array}$ & $\begin{array}{l}\text { Sourdough addition increased the cell volume significantly in } \\
\text { sorghum (+61 \%), teff (+92 \%) and wheat sourdough breads } \\
(+78 \%) \text {. Therefore, crumb porosity was significantly } \\
\text { increased in all gluten-free and wheat sourdough breads. Shelf } \\
\text { life for sourdough breads was one (teff and oat) and } 3 \text { days } \\
\text { (wheat) and was not prolonged by sourdough addition. The } \\
\text { result of the present study showed that chosen gluten-free } \\
\text { flours are able to serve as substrates for } L \text {. plantarum FST } 1.7\end{array}$ & [42] \\
\hline Injera & $\begin{array}{l}\text { Evaluate the effect of varieties and } \\
\text { blending ratio on nutritional and sensory } \\
\text { acccebtability of the blended injera. For } \\
\text { the study, a factorial design of two } \\
\text { factors were used (V1=white teff, } \\
\text { V2=red teff and V3=mixture of the two) } \\
\text { and blending ratios of teff to moringa } \\
\text { (B0=100:0, B1=95:5, B2=92.5:7.5 and } \\
\text { B3=90:10). }\end{array}$ & $\begin{array}{l}\text { Mixed teff with } 10 \% \text { moringa contained } 45.74,172.70,5.85 \\
\text { and } 8.55 \mathrm{mg} / 100 \mathrm{~g} \text { Fe, Ca, Zn and beta-carotene contents } \\
\text { respectively which were higher than the control. Even though } \\
\text { white teff with } 10 \% \text { moringa was highly selected, all were in } \\
\text { the range of } 5.05 \text { to } 5.77 \text { with moderate acceptability, but } \\
\text { color of red teff with } 10 \% \text { moringa had well lowest value } \\
\text { (1.53) falling in the dislike moderately class. }\end{array}$ & [43] \\
\hline Bread & $\begin{array}{l}\text { Studies the influence of the addition of } \\
\text { teff flour (5,10 and 20\%) and different } \\
\text { dried (buckwheat or rice) or fresh (with } \\
\text { Lactobacillus helveticus) sourdoughs on } \\
\text { the sensory quality and consumer } \\
\text { preference of gluten-free (GF) breads. }\end{array}$ & $\begin{array}{l}\text { The visual appearance of breads with } 20 \% \text { teff was highly } \\
\text { appreciated by consumers, while bread combining } 10 \% \text { teff } \\
\text { and rice sourdough was preferred in terms of flavour. This } \\
\text { work highlights the great potential of combining teff and } \\
\text { selected sourdoughs to obtain gluten-free breads with target } \\
\text { attributes and improved sensory profile. }\end{array}$ & [12] \\
\hline Cookies & $\begin{array}{l}\text { Teff-oat composites were developed } \\
\text { using gluten free teff flour containing } \\
\text { essential amino acids with oat products } \\
\text { containing beta-glucan }\end{array}$ & $\begin{array}{l}\text { The elastic properties of teff-OBC (oat bran concentrate) and } \\
\text { teff-WOF (whole oat flour) doughs were slightly higher than } \\
\text { teff dough. Differences were found in geometrical and } \\
\text { textural properties of the doughs and cookies. Overall, the } \\
\text { teff-oat cookies were acceptable in colour, flavour, and } \\
\text { texture. }\end{array}$ & [44] \\
\hline
\end{tabular}


This study examined the effects of substitution of rice flour (control) with teff flour at 25\%, 50\%, 75\% and 100\% on the physical, textural, and sensory characteristics of gluten free muffins. A decrease in height of baked muffins was observed with an increase in the percentage of teff flour. Muffins with $75 \%$ and $100 \%$ teff flour had very viscous batters with significantly lower line spread tests compared to control rice muffins. Textural measurements showed no significant difference between the control, 25 and $50 \%$ teff muffins but the 75 and 100\% teff muffins were significantly harder. Substitutions up to $50 \%$ with teff flour were acceptable to the panelists. Friedman's rank test showed no significant difference in the overall liking between control, $25 \%$ and $50 \%$ teff muffins. This study demonstrates that substituting $50 \%$ rice flour with teff not only produces acceptable gluten free muffins, but these are more nutritious because of their higher protein (27\%), iron (2095\%), calcium (25\%) and fiber (221\%) contents [40].

Was examined the effect of 25 and $50 \%$ replacement with teff flour on the physical, textural and sensory properties of gluten free sugar and peanut butter cookies. Compared to control cookies, teff cookies exhibited decreased heights, weights and spreads. Texture analysis of the cookies done showed teff flour substitutions to have decreased hardness, and initial stiffness compared to control cookies. The teff flour sugar cookies were also found to be more brittle and less tough compared to control cookies. Subjective analysis $(\mathrm{n}=76)$ showed no significant difference in flavor, taste, and appearance between the control and the teff flour cookies. Panelists preferred the control and 25\% teff cookie over the 50\% in case of sugar cookie, but no such preference was observed in case of peanut butter cookies. These results show that nutrient dense teff flour can be a good alternative and can also improve the taste and flavor of gluten free cookies [28].

Was determined formulations for the production of egg pasta from oat and teff flour, being that wheat flour was useding as a control. The results showed that the mechanical texture of oat and teff pasta was comparable to wheat pasta, however, elasticity was significantly reduced. Compositional analysis showed that regarding fibre and mineral content, oat and teff samples are nutritionally superior to wheat. Upon cooking, a distinct outer layer can be observed, resulting from protein denaturation and starch gelatinisation. Thus, the results clearly showed that teff and oat flour can be used to produce gluten-free pasta of acceptable texture [37]

The effect of grain teff flour substitution with flaxseed on quality and functionality of injera was analyzed by Girma, Bultosa, and Bussa, [41]. Injera from teff was substituted with two flaxseed forms at 3\%, 6\% and $9 \%$ and control injera showed substitution had a significant effect on injera proximate, energy, titratable acidity (TA), total phenolics (TP) contents and sensory acceptability. With $9 \%$ flour and whole flaxseed substitution, percentage energy, moisture, ash, crude protein, fiber and TA increase were 3.5, 27.3, 25.9, 20.4, 114.3 and 10.1, respectively. Carbohydrate and $\mathrm{pH}$ were high for control. In all injera samples, condensed tannins and free fatty acid were insignificant. With an increase in the flaxseed substitution, most sensory acceptance increased, whereas injera eyes and colour decreased and appeared superior for control (100\% teff injera). The $9 \%$ flaxseed-substituted injera showed good proximate nutritional and energy contents of functional potential of high in dietary fiber, alpha linolenic acid, lignans, proteins and TP of anti-oxidant nature.

Sourdoughs were produced from buckwheat, oat, quinoa, sorghum, teff and wheat flour using the heterofermentative lactic acid bacteria Lactobacillus plantarum FST 1.7 and added to a basic bread formulation of flour from the same grain type (20\% addition level). Furthermore, sourdough addition led to decreased dough strength resulting in softer dough. No influences on specific volume and hardness on day of baking were found for gluten-free sourdough breads. The staling rate was reduced in buckwheat (from 8 \pm 2 to $6 \pm 2 \mathrm{~N} /$ day) and teff sourdough bread (13 \pm 1 to 10 $\pm 4 \mathrm{~N}$ /day), however, not significantly in comparison with the control breads. On the contrary, in wheat sourdough bread, the staling rate was significantly reduced (2 \pm 1 $\mathrm{N} /$ day) in comparison with control bread ( $\pm \pm 1 \mathrm{~N} /$ day). Sourdough addition increased the cell volume significantly in sorghum $(+61 \%)$, teff $(+92 \%)$ and wheat sourdough breads (+78 \%). Therefore, crumb porosity was significantly increased in all gluten-free and wheat sourdough breads. Shelf life for sourdough breads was one (teff and oat), two (buckwheat, quinoa and sorghum) and 3 days (wheat) and was not prolonged by sourdough addition. The result of the present study showed that chosen gluten-free flours are able to serve as substrates for L. plantarum FST 1.7 [42].

This study was conducted to evaluate the effect of varieties and blending ratio on nutritional and sensory acccebtability of the blended injera. For the study, a factorial design of two factors were used (V1=white teff, $\mathrm{V} 2=$ red teff and $\mathrm{V} 3=$ mixture of the two) and blending ratios of teff to moringa $(\mathrm{B} 0=100: 0, \quad \mathrm{~B} 1=95: 5$, B2=92.5:7.5 and B3=90:10). The interaction of variety and blending ratio had significant effect on nutritional and antinutritional content of injera. Injeras of white teff with $10 \%$ moringa contained 63.24, 19.80, 1.88 and 4.44\% moisture, protein, fiber and ash contents respectively and were higher than those of the control. Injeras of red teff with $10 \%$ moringa contained 64.84, 18.79, 2.53 and $4.72 \%$ moisture, protein, fiber and ash contents respectively and were higher than those of the control. Injeras of mixed teff with $10 \%$ moringa contained 62.29 , 17.43, 1.59 and $4.85 \%$ moisture, protein, fiber and ash contents respectively and were higher than in injeras of the control. Overall, reduced fat, carbohydrates and energy contents were obtained after blending. Concerning minerals and vitamins, injeras of white teff with $10 \%$ moringa contained 27.87, 216.31, 6.22 and7.48 mg/100 g $\mathrm{Fe}, \mathrm{Ca}, \mathrm{Zn}$ and beta carotene contents respectively which were higher than the control. Red teff with $10 \%$ moringa blended injera contained 57.06, 330.80, 6.30 and 9.56 $\mathrm{mg} / 100 \mathrm{~g}$ Fe, $\mathrm{Ca}, \mathrm{Zn}$ and beta-carotene contents respectively which were higher than the control. Mixed teff with $10 \%$ moringa contained 45.74, 172.70, 5.85 and $8.55 \mathrm{mg} / 100 \mathrm{~g} \mathrm{Fe}, \mathrm{Ca}, \mathrm{Zn}$ and beta-carotene contents respectively which were higher than the control. Overall phosphorous, tannin and phytic acid were reduced after blending. There were reductions in score of all sensory attributes after blending. The lowest scores in all attributes were from injeras of all teff varities with $10 \%$ moringa. Even though white teff with $10 \%$ moringa was highly 
selected, all were in the range of 5.05 to 5.77 with moderate acceptability, but color of red teff with $10 \%$ moringa had well lowest value (1.53) falling in the dislike moderately class [43].

This work studies the influence of the addition of teff flour (5, 10 and 20\%) and different dried (buckwheat or rice) or fresh (with Lactobacillus helveticus) sourdoughs on the sensory quality and consumer preference of glutenfree (GF) breads. A set of 10 GF breads combining these ingredients was submitted to sensory descriptive analysis performed by a trained panel. The combination of teff (10\%) with cereal sourdough (rice or buckwheat) enhanced bread aroma, increasing the fruity, cereal and toasty notes. High levels of teff (20\%) and Lb. helveticus sourdough induced a decrease on the loaf area. The visual appearance of breads with $20 \%$ teff was highly appreciated by consumers, while bread combining $10 \%$ teff and rice sourdough was preferred in terms of flavour. The bitter taste of buckwheat sourdough was generally considered as a negative attribute. However, a group of consumers liked bitter bread as they associated it to a traditional, artisan, "malty-like” product. This work highlights the great potential of combining teff and selected sourdoughs to obtain gluten-free breads with target [12].

Teff-oat composites were developed using gluten free teff flour containing essential amino acids with oat products containing beta-glucan. The teff-oat composites were used in sugar cookies for improving nutritional and physical properties. Teff and its composites had higher water holding capacities compared to wheat flour. The pasting properties were not significantly influenced by $20 \%$ oat product replacements in teff-oat composites. The pasting viscosities of teff-OBC and teff-WOF 4:1 composites were similar to teff flour, but they were all higher than wheat flour. The elastic properties of teffOBC (oat bran concentrate) and teff-WOF (whole oat flour) doughs were slightly higher than teff dough. Differences were also found in geometrical and textural properties of the doughs and cookies. Overall, the teff-oat cookies were acceptable in colour, flavour, and texture. In general, teff-oat composites are very suitable for preparing cookies that were acceptable in colour, flavour and texture qualities compared to the cookies with wheat flour [44].

\section{Practical Applications}

Teff grain can be used as a substitute for wheat flour and other cereals, works well in a number of recipes, as well can be utilized in foods for people with celiac disease. It also has high levels of magnesium, potassium, zinc, copper, manganese, choline, vitamin B3 (niacin), vitamin B6, thiamin, pantothenic acid, and riboflavin. Therefore, teff could be beneficial for coeliac disease. Gluten-free bread quality is dependent on ingredients and additives combination, but also processing can provide a way to improve bread quality. Nutritive value of the gluten-free breads must be always in mind when setting up recipes, for obtaining nutritionally balanced bread. Thus, nutritional quality is an important asset when developing gluten-free breads, and different strategies for improving are important.

\section{Conflict of Interest}

The authors declare that they have no conflict of interest.

\section{References}

[1] Arendt, E.K., Zannini, E. "10 - Teff. Cereal Grains for the Food and Beverage Industries,” A volume in Woodhead Publishing Series in Food Science, Technology and Nutrition: 351-368, 369. 2013.

[2] Adebowale, A. R. A., Emmambux, M. N., Beukes, M., Taylor, J. R. "Fractionation and characterization of teff proteins," J Cereal Sci, 54(3). 380-386. 2011.

[3] Lovis, L. J. "Alternatives to wheat flour in baked goods", Cereal Foods World, 48(2). 61. 2003.

[4] Assefa, K., Yu, J. K., Zeid, M., Belay, G., Tefera, H., Sorrells, M. E. "Breeding tef [Eragrostis tef (Zucc.) trotter]: conventional and molecular approaches,” Plant Breed, 130(1). 1-9. 2011.

[5] Habtegebrial, K., Singh, B. R., Haile, M. "Impact of tillage and nitrogen fertilization on yield, nitrogen use efficiency of tef (Eragrostis tef (Zucc.) Trotter) and soil properties,” Soil Till Res, 94(1). 55-63. 2007.

[6] FAO. "Analysis of price incentives for Teff in Ethiopia," Technical notes series, MAFAP, by Assefa B. Demeke M., Lanos B, Rome. http://www.fao.org/3/a-i4523e.pdf. 2015.

[7] Girma, D., Assefa, K., Chanyalew, S., Cannarozzi, G., Kuhlemeier, C., Tadele, Z. "The origins and progress of genomics research on Tef (Eragrostis tef),” Plant Biotechnol J, 12(5). 534-540. 2014.

[8] Assefa, K., Chanyalew, S., Tadele, Z. "Tef, Eragrostis tef (Zucc.) Trotter,” Millets and Sorghum: Biology and Genetic Improvement 226p. 2016.

[9] Haileselassie, H., Araya, A., Habtu, S., Meles, K. G., Gebru, G., Kisekka, I., Foster, A. J. "Exploring optimal farm resources management strategy for Quncho-teff (Eragrostis tef (Zucc.) Trotter) using AquaCrop model," Agric Water Manage, 178. 148-158. 2016.

[10] Abebe, W., Collar, C., Ronda, F. "Impact of variety type and particle size distribution on starch enzymatic hydrolysis and functional properties of tef flours," Carbohyd Polym, 115. 260-268. 2015.

[11] Abebe, Y., Bogale, A., Hambidge, K. M., Stoecker, B. J., Bailey, K., Gibson, R. S. "Phytate, zinc, iron and calcium content of selected raw and prepared foods consumed in rural Sidama, Southern Ethiopia, and implications for bioavailability," J Food Compos Anal, 20(3). 161-168. 2007.

[12] Campo, E., del Arco, L., Urtasun, L., Oria, R. and Ferrer-Mairal, A. "Impact of sourdough on sensory properties and consumers' preference of gluten-free breads enriched with teff flour," J Cereal Sci, 67. 75-82. 2016.

[13] Kotásková, E., Sumczynski, D., Mlček, J., Valášek, P. "Determination of free and bound phenolics using HPLC-DAD, antioxidant activity and in vitro digestibility of Eragrostis tef," $J$ Food Compos Anal, 46. 15-21. 2016.

[14] Gebremariam, M. M., Zarnkow, M., Becker, T. “Thermal stability of starch degrading enzymes of teff (Eragrostis tef) malt during isothermal mashing," Process Biochem, 48(12). 1928-1932. 2013.

[15] Gebremariam, M. M., Zarnkow, M., Becker, T. “Teff (Eragrostis tef) as a raw material for malting, brewing and manufacturing of gluten-free foods and beverages: a review," J Food Sci Technol, 51(11). 2881-2895. 2014.

[16] Gallagher, E., Gormley, T.R., Arendt, E.K. "Recent advances in the formulation of gluten-free cereal-based products," Trends Food Sci Technol, 5(3). 143-52. 2004.

[17] Suliburska, J., Krejpcio, Z. "Evaluation of the content and bioaccessibility of iron, zinc, calcium and magnesium from groats, rice, leguminous grains and nuts”. J Food Sci Technol, 51(3). 589594. 2014.

[18] Bultosa, G., Taylor, J.R.N. "Teff. Encyclopedia of Grain Science 281-290," 2004

[19] Baye, K. "Teff: nutrient composition and health benefits", Internationl Food Policy Research Institute 67. 2014.

[20] Bultosa, G. "Physicochemical characteristics of grain and flour in 13 tef [Eragrostis tef (Zucc.) Trotter] grain varieties,” J App Sci Res, 3(12). 2042-2051. 2007. 
[21] Helbing, J. "Konfokale laser scanning-mikroskopie und rasterelektronenmikroskopie zur beobachtung der mälzung verschiedener zerealien und pseudozerealien". Technische Universität München, Germany. 2009.

[22] El-Alfy, T. S., Ezzat, S. M., Sleem, A. A. "Chemical and biological study of the seeds of Eragrostis tef (Zucc.) Trotter," Nat Prod Res, 26(7). 619-629. 2012.

[23] Bekabil, F., Befekadu, B., Simons, R. Tareke, B. "Strengthening the tef value chain in Ethiopia," Ethiopian ATA, Ethiopian Agricultural Transformation Agency. Table off arm level profitability analysis. 2011.

[24] Alaunyte, I., Stojceska, V., Derbyshire, E., Plunkett, A., Ainsworth, P. "Iron-rich Teff-grain bread: an opportunity to improve individual's iron status," Proceedings of the Nutrition Society, 69 (OCE1), E105. 2010.

[25] Boka, B., Woldegiorgis, A. Z., Haki, G. D. "Antioxidant properties of Ethiopian traditional bread (injera) as affected by processing techniques and tef grain [Eragrostis tef (Zucc.) Trotter] varieties," Can Chem Trans, 1. 7-24. 2013.

[26] Forsido, S. F., Rupasinghe, H. V., Astatkie, T. "Antioxidant capacity, total phenolics and nutritional content in selected ethiopian staple food ingredients," Int J Food Sci Technol Nutr, 64(8). 915-920. 2013.

[27] Marti, A., Marengo, M., Bonomi, F., Casiraghi, M. C., Franzetti, L., Pagani, M. A., Iametti, S. Molecular features of fermented teff flour relate to its suitability for the production of enriched glutenfree bread. LWT-Food Sci. Technol, 78. 296-302. 2017.

[28] Kenney, E. S., Butler, C., Moore, C., Bhaduri, S., Ghatak, R., Navder, K. P. "The effect of substituting teff flour in gluten-free sugar cookies and peanut butter cookies," J Am Diet Ass, 111(9). A63. 2011.

[29] Abebe, W., Ronda, F. "Rheological and textural properties of tef [Eragrostis tef (Zucc.) Trotter] grain flour gels," J Cereal Sc, 60(1).122-130. 2014.

[30] Hager, A. S., Wolter, A., Jacob, F., Zannini, E., Arendt, E. K. "Nutritional properties and ultra-structure of commercial gluten free flours from different botanical sources compared to wheat flours," J Cereal Sc, 56(2). 239-247. 2012.

[31] Dijkstra, A., Polman, J., van Wulfften-Palthe, A., Gamboa, P. A. van Ekris, L. "Survey on the nutritional and health aspects of teff (Eragrostis Tef). Memorias,” Red-Alfa Lagrotech. Comunidad Europea 382. 2008.

[32] Bultosa, G., Hall, A. N., Taylor, J. "Physico - chemical characterization of grain Tef [Eragrostis tef (Zucc.) Trotter] starch,” Starch - Stärke, 54(10).461-468. 2002.
[33] Alaunyte, I., Stojceska, V., Plunkett, A., Ainsworth, P., Derbyshire, E. "Improving the quality of nutrient-rich Teff (Eragrostis tef) breads by combination of enzymes in straight dough and sourdough breadmaking," J Cereal Sc, 55(1). 22-30. 2012.

[34] Malkal teff. Teff and Resistant Starch. https://teffco.com/teff-andresistant-starch/ [Acess in: 03 april 2017.

[35] Bultosa, G., Taylor, J. "Chemical and physical characterization of grain Tef [Eragrostis tef (Zucc.) Trotter] starch granule composition,” Starch Stärke, 55(7). 304-312. 2003.

[36] Beri, G. "Physico-chemical and functional properties of grain tef (Eragrotis tef (Zucc.) Trotter] starch,” 2016.

[37] Hager, A. S., Lauck, F., Zannini, E., Arendt, E. K. "Development of gluten-free fresh egg pasta based on oat and teff flour," Eur Food Res Technol, 235(5). 861-871. 2012.

[38] Abebe, W., Ronda, F., Villanueva, M., Collar, C. "Effect of tef [Eragrostis tef (Zucc.) Trotter] grain flour addition on viscoelastic properties and stickiness of wheat dough matrices and bread loaf volume," Eur Food Res Technol, 241(4). 469-478. 2015.

[39] Moreno, M. D. L., Comino, I., Sousa, C. "Alternative grains as potential raw material for gluten-free food development in the diet of celiac and gluten-sensitive patients," Austin J Nutr Food Sci, 2(3). 1016. 2014.

[40] Valcarcel, M., Ghatak, R., Bhaduri, S., Navder, K. P. "Physical, textural and sensory characteristics of gluten-free muffins prepared with teff flour (Eragrostis Tef (zucc) Trotter)," J Acad Nutr Diet, 112(9). A58. 2012.

[41] Girma, T., Bultosa, G., Bussa, N. "Effect of grain tef [Eragrostis tef (Zucc.) Trotter] flour substitution with flaxseed on quality and functionality of injera," Int J Food Sci Technol, 48(2). 350-356. 2013.

[42] Wolter, A., Hager, A. S., Zannini, E., Czerny, M., Arendt, E. K. "Impact of sourdough fermented with Lactobacillus plantarum FST 1.7 on baking and sensory properties of gluten-free breads," Eur Food Res Technol, 239(1). 1-12. 2014.

[43] Tarekegh, G. "Blending of Teff (Eragrostis teff) varietes with Moringa (Moringa Oleifera) leaf powder to improve the nuturitonal content of injera," (Doctoral dissertation, Harmaya University). Haramaya University, Haramaya. 91p. 2015.

[44] Inglett, G. E., Chen, D., Liu, S. X. "Physical properties of gluten free sugar cookies containing teff and functional oat products," $J$ Food Res, 5(3). 72. 2016. 